\title{
XRD, OPTICAL AND VIBRATIONAL PROPERTIES OF ANNEALED CADMIUM SULFIDE FILMS
}

\author{
Sabiha AKSAY* \\ Department of Physics, Eskişehir Technical University, Eskişehir, Turkey
}

\begin{abstract}
Cadmium sulfide (CdS) films have been formed using an ultrasonic spray pyrolysis method. These films were annealed at a temperature range of $200-500^{\circ} \mathrm{C}$ in air for 5 hours. To investigate the effects of annealing on the vibrational, structural, optical and morphological properties of cadmium sulfide films, X-ray diffraction (XRD), Raman spectroscopy, Fourier transform infrared (FTIR) spectroscopy, UV-visible spectroscopy (UV-vis) and atomic force microscopy (AFM) were used, respectively. The XRD spectra indicated that the films have polycrystalline hexagonal nature. According to XRD results, increase in the annealing temperature causes an increase in crystallite size. The optical band gap of the CdS films have been calculated at different annealing temperatures and are found to be in the range of 2.40-2.44 eV. Raman results exhibited two peaks attributed to the $1 \mathrm{LO}\left(300 \mathrm{~cm}^{-1}\right)$ and $2 \mathrm{LO}\left(601 \mathrm{~cm}^{-1}\right)$ modes of hexagonal CdS. The chemical bonding has been analyzed by FTIR spectra. The vibrational peaks in the FTIR spectra of the films located at 550-715 and $844-1160 \mathrm{~cm}^{-1}$ correspond to the Cd-S and C$\mathrm{O}$ phonon modes, respectively. The morphological properties of all the films were determined by AFM images. The annealing temperature caused a change in color images of films.
\end{abstract}

Keywords: Annealed CdS film; XRD; Raman; Optical properties

\section{INTRODUCTION}

In recent years, the works on structural, optical and vibrational properties of the II-VI group wide optical band gap semiconductors have been increasing. Cadmium sulfide $(\mathrm{CdS})$ is an important semiconductor with wide band gap, $2.4 \mathrm{eV}$ at room temperature and n-type conductivity [1]. CdS thin film has been used worldwide as a window layer in the form of $\mathrm{CdS} / \mathrm{CuInSe} 2, \mathrm{CdS} / \mathrm{CdTe}$ and $\mathrm{CdS} / \mathrm{Cu}_{2} \mathrm{~S}$ thin film solar cells. It is well known that properties and applications of the semiconducting materials significantly depend on their size and morphology. Cadmium sufide exists in two crystalline forms: hexagonal phase and cubic phase, and it is possible to grow CdS films in both these phases. The formation of cubic or hexagonal structure depend on many factors including the deposition method. While the cubic structure is preferred to increase the potential applicability of $\mathrm{CdS}$ for optoelectronic devices, the hexagonal $\mathrm{CdS}$ is a preferable phase for solar cell applications [1]. The semiconductor materials to be used as glazing material in solar cell applications should have two basic characteristics. These are low impedance and high transmittance. CdS always has high impedance independent of the production method. It has also applications in light-emitting diodes (LEDs), gas detectors, photovoltaic cells and nonlinear optics [24]. Particularly in recent years, spintronic devices such as spin-valve transistors, ultrafast optical switches and optical isolators have stimulated great passions of many researchers for introducing room temperature ferromagnetism in CdS materials. Cadmium sulfide films with good structural, vibrational and optical qualities have been reported and in these reports, many techniques such as sol-gel [5], radio frequency sputtering [6], thermal evaporation [7], chemical bath deposition (CBD) [8-10] and ultrasonic spray pyrolysis (USP) [1, 11-13] have been used. From all of these techniques, USP is a cheaper and an easier way. It also presents the production characteristics of a large area semiconductor which can be used for related solar applications. CdS films having good quality have been grown using the USP technique [1,11-13]. The structure of the CdS films can be changed by either preparation condition or preparation method. The annealing temperature $\left(T_{a}\right)$ is one of the most important parameters which

*Corresponding Author: saksay@anadolu.edu.tr

Received: 22.05.2018 Accepted: 08.11.2018 
affect the physical properties of thin films such as the structural, vibrational and optical properties [14, 15]. Chander and Dhaka [16], by using Electron Beam Vacuum Evaporation Method to obtain CdZnTe thin film, demonstrated that optical absorption is increased with increasing annealing temperature, resulting in decrease in optical energy gap. As a result, an increase in absorption intensity was observed with increasing with $T_{a}$, according to the FTIR study. Arunraja et al. [17] reported that CdS grain sizes tended to increase by increasing annealing temperature. It was clearly observed that CdS grains were agglomerated to form clusters with compact crystalline nature when annealing temperature increased. Meher et al. [5] observed that the films annealed at 573, 623 and $673 \mathrm{~K}$ exhibited near infra-red emissions corresponding to the mid-gap cadmium vacancies and interstitials, which, in turn, may cause defects related to photoluminescence. Kong et al. [8] observed a shifting in energy band gap of cadmium sulfide, which is deposited by CBD method, depending on the annealing from $2.45 \mathrm{eV}$ to $2.32 \mathrm{eV}$. This clearly resulted in shifting to longer wavelength and remarkably enhanced absorption of cadmium sulfide films in the visible region.

In this study, CdS films have been deposited on glass substrates by the USP technique and effects of the annealing temperature $\left(T_{a}\right)$ on the structural, vibrational (Raman and FTIR) and optical properties of the films have been examined. The changes in the vibrational, structural and optical properties have been discussed depending on the $T_{a}$.

\section{EXPERIMENTAL DETAIL}

CdS films were prepared by USP method at $300^{\circ} \mathrm{C}$ substrate temperature. The experimental USP setup for the growth of CdS films has been fully described before [12]. The solution is usually made by dissolving salts of the constituent atoms of desired compound in aqueous medium. Cadmium chloride $\mathrm{CdCl}_{2} .2 \mathrm{H}_{2} \mathrm{O}(0.05 \mathrm{M})$ and thiourea $\mathrm{NH}_{2} \mathrm{CSNH}_{2}(0.05 \mathrm{M})$ were used as $\mathrm{Cd}$, and $\mathrm{S}$ sources, respectively. The amorphous glass substrates cut in determined size before spraying were at first washed with distilled water and boiled in detergent distilled water and then dried by rinsing. The distance between the spraying nozzle and the substrate was set about $30 \mathrm{~cm}$. This distance adjusting usually around $30-40 \mathrm{~cm}$ affects the quality of films. Nitrogen $\left(\mathrm{N}_{2}\right)$ gas was used as the carrier gas. The surface temperature of glass substrate was measured by iron-constantan thermocouple. After deposition, the film was inserted to a furnace and annealed in air at $200,300,400$ and $500^{\circ} \mathrm{C}$ for $5 \mathrm{~h}$. Thicknesses $(t)$ of the CdS films were determined by an Ellips SC620 Spectroscopic Ellipsometer. The thicknesses of the CdS films asdeposited and annealed at $200,300,400$ and $500^{\circ} \mathrm{C}$ have determined to be 228.06, 280.38, 119.26, 88.04, and $280.92 \mathrm{~nm}$, respectively. Optical absorption spectra were carried out using Shimadzu UV 2450 spectrophotometer. The energy band gaps $\left(E_{g}\right)$ of the CdS films were found by UV-vis measurements. The structural analysis of the CdS films was founded by Phillips X-ray diffractometer using $\lambda_{\mathrm{CuKa}}=1.5406 \AA$ radiation. The X-ray diffraction recorded were scanned in $2 \theta$ range of $20^{\circ}-70^{\circ}$. The Fourier transform infrared spectrum was recorded on Perkin Elmer 2000 FTIR spectrometer. The Raman spectrum were recorded in the wavenumber range of $200-1000 \mathrm{~cm}^{-1}$ on a Bruker Senterra Dispersive Raman instrument. The surface images of the CdS films were investigated by atomic force microscopy (Solver PRO-NSG20). All measurements were performed at room temperature.

\section{RESULTS AND DISCUSSIONS}

\subsection{Structural Characterization of the CdS films}

The crystal structure of the CdS films was analyzed by the X-ray diffraction method. Figure 1 shows the XRD patterns of the as-deposited and annealed films. The planes of the hexagonal wurtzite $\mathrm{CdS}$ crystal structure correspond to the (100), (002), (1 0 1), (110), (112) and (203) Miller indices (Fig. 1). The obtained spectra show highly good matching with X-ray powder file data for the hexagonal $\mathrm{CdS}$ (ASTM card no 006-314 and 041-1049) [18]. As seen in Fig. 1, as the annealing temperature increases, 
the crystallization of films has increased. The best crystallization was observed in the annealed film at $500^{\circ} \mathrm{C}$. From the Figure 1, sulphur peaks have also seen at $29^{\circ}$ and $45^{\circ}[19]$.

The fundamental equation to find the crystallite size was the Scherrer formula [20]. This equation is given below,

$$
d=\frac{\lambda}{D \cos \theta}
$$

where $d$ is the crystallite size, $\lambda$ is the X-ray wavelength, $D$ is the angular line width of the halfmaximum intensity and $\theta$ is the Bragg angle. The crystallite size of the CdS films as-deposited and annealed at $200,300,400$ and $500^{\circ} \mathrm{C}$ have been determined to be $29,31,33,34$, and $35 \mathrm{~nm}$, respectively. These results show that the annealing temperature increases as the crystallite size increases. The increase in temperature causes an increase in crystallite size as it induces migration of grain boundaries.

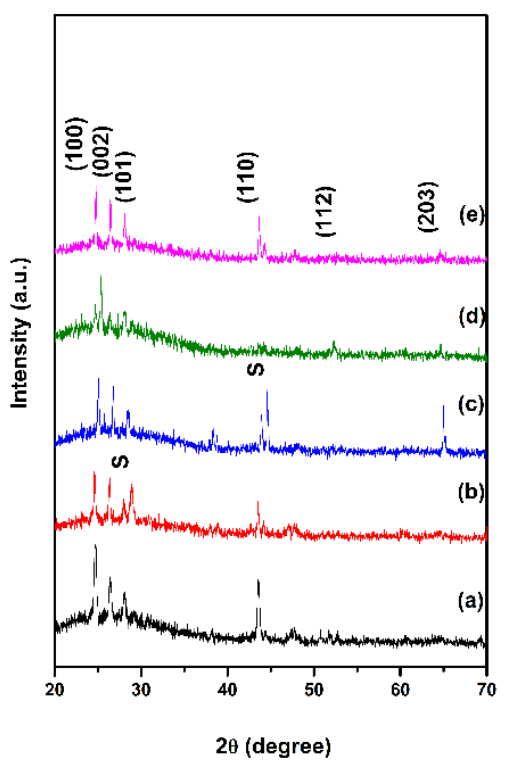

Figure 1. XRD patterns of the CdS films (a) as-deposited and annealed at (b) $200^{\circ} \mathrm{C}$ (c) $300^{\circ} \mathrm{C}$, (d) $400^{\circ} \mathrm{C}$ and (e) $500^{\circ} \mathrm{C}$

\subsection{Vibrational Properties of the CdS Films}

Raman scattering and FTIR spectra are an important tool to identify the structural characteristic of the films, in which, mostly examine the disordered and chemical structures in the deposited films. Figure 2 shows the Raman spectra of the CdS films in the frequency region $200-1000 \mathrm{~cm}^{-1}$. The fundamental longitudinal optical mode (1LO) was observed at $300 \mathrm{~cm}^{-1}$. And this spectra, the second overtone (2LO) mode were also observed at $601 \mathrm{~cm}^{-1}$. The two Raman active modes are characteristics of CdS films confirming the hexagonal wurtzite structure corresponds with the literature [5, 12,13,21]. It is shown that this Figure, there is also a shift in peak position and a decrease in peak intensity. The slight shifting of the peak position and decrease in the peak intensity may be assigned with the oxygen incorporation into the lattice. 


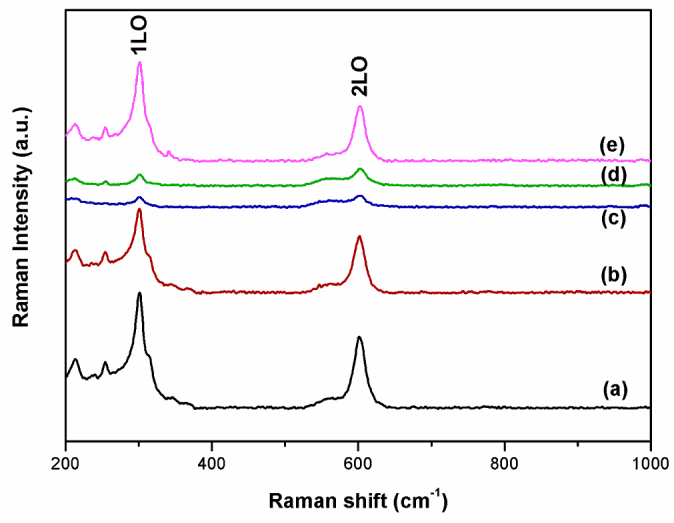

Figure 2. Raman spectra of CdS films: (a) as-deposited and annealed at (b) $200^{\circ} \mathrm{C}$ (c) $300^{\circ} \mathrm{C}$, (d) $400^{\circ} \mathrm{C}$ and (e) $500^{\circ} \mathrm{C}$

Figure 3 shows the FTIR spectra of the CdS films. There is no important difference between the spectra of the as-deposited and annealed films. The $\mathrm{Cd}-\mathrm{S}$ and $\mathrm{C}-\mathrm{O}$ phonon modes are seen in the wavenumber range of $550-715 \mathrm{~cm}^{-1}$ and $844-1160 \mathrm{~cm}^{-1}$, respectively. The band at about $1259 \mathrm{~cm}^{-1}$ is attributed to the phonon mode vibration of the $\mathrm{C}-\mathrm{O}$ bond $[1,12,13,22]$. The spectra showed that the absorption was at $2358 \mathrm{~cm}^{-1}$, which is from carbon dioxide molecule in air and is not connected to the cadmium sulfide film.



Figure 3. FTIR spectra of CdS films: (a) as-deposited and annealed at (b) $200{ }^{\circ} \mathrm{C}$ (c) $300{ }^{\circ} \mathrm{C}$, (d) $400{ }^{\circ} \mathrm{C}$ and (e) $500^{\circ} \mathrm{C}$

\subsection{Optical Properties of the CdS Films}

The optical absorption edge was determined by the optical absorption, a simple method that provides explanation for the features concerning the optical bad gap $\left(E_{g}\right)$ of the film. The $E_{g}$ is looked at according to the well-known relation [23]:

$$
\alpha E=A\left(E-E_{g}\right)^{m}
$$

where $A$ is a constant, $\alpha$ is the absorption coefficient, $E$ is the photon energy, and $m$ is a constant equal to $1 / 2$ for a direct band gap semiconductor. Figure 4 and 5 shows the plots of $(\alpha E)^{2}$ vs $E$ for the asdeposited and the annealed films. As seen from the figures, the CdS films have allowed direct band gap structure. The optical band gap values can be seen by assuming the linear portion of the plot $(\alpha E)^{2}$ vs $E$ 
to $\alpha=0$ and given in Figure 4 and 5. It also can be seen in these Figure, the optical band gap changes from $2.40 \mathrm{eV}$ to $2.44 \mathrm{eV}$ with an annealing temperature going up from $200^{\circ} \mathrm{C}$ to $500^{\circ} \mathrm{C}$. The optical band gap values of CdS films are in accordance with the literature data $[5,8,13,15,24,25]$. These values of the optical band gap may be suggested as being suitable as a window layer fabrication for thin film solar cells.

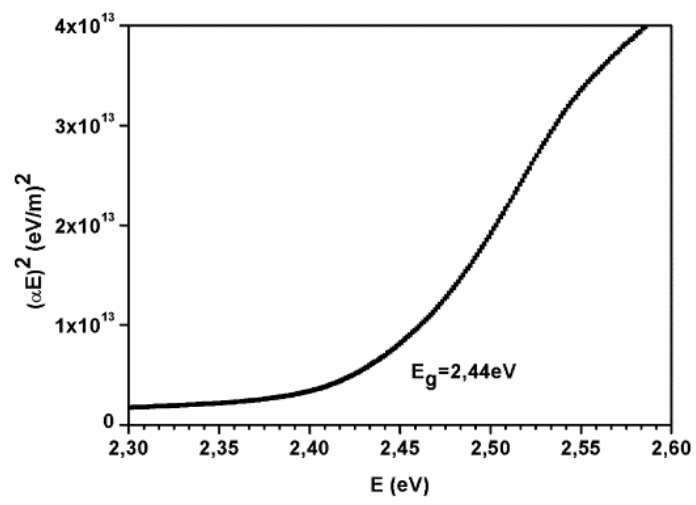

Figure 4. Plot of $(\alpha E)^{2}$ vs. $E$ of as-deposited cadmium sulfide films.

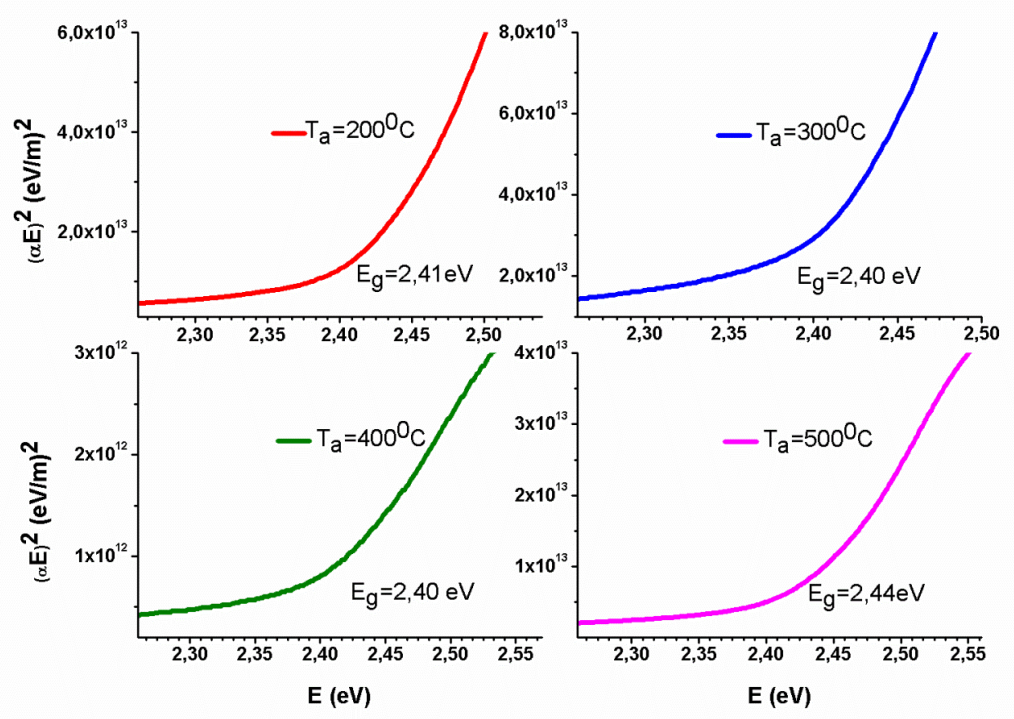

Figure 5. Plot of $(\alpha E)^{2}$ vs. $E$ of CdS films: (a) as-deposited and annealed at (b) $200^{\circ} \mathrm{C}$ (c) $300^{\circ} \mathrm{C}$, (d) $400{ }^{\circ} \mathrm{C}$ and (e) $500^{\circ} \mathrm{C}$

The optical transmittance spectra of cadmium sulfide and annealed cadmium sulfide films in the wavelength range of 400-800 $\mathrm{nm}$ are shown in Figure 6. Where the after annealing temperature the average transmittance was a little higher up to $85 \%$ in the visible region, showing a rise in optical and crystalline quality. The change in the optical transmittance where the $T_{a}$ was because of changings in the film thickness. Also a rise in the annealing of grains caused a higher surface roughness [16]. 


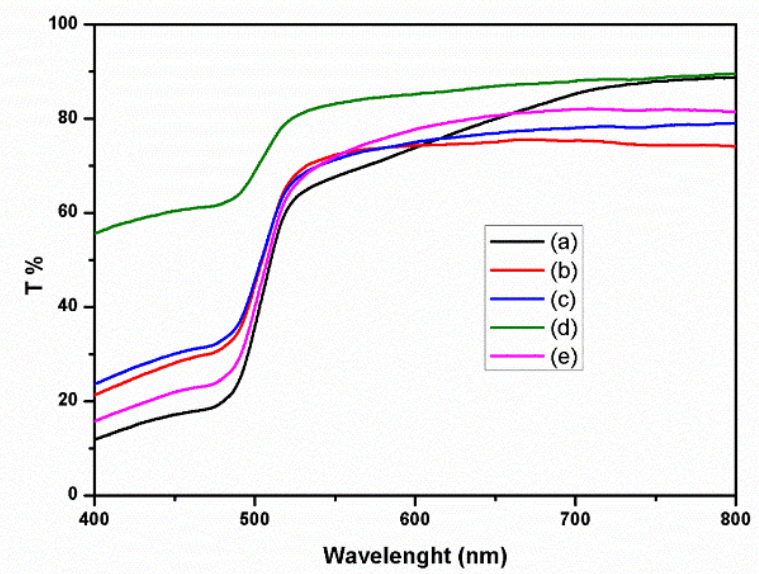

Figure 6. UV-vis optical transmission spectra of CdS films: (a) as-deposited and annealed at (b) $200^{\circ} \mathrm{C}$ (c) $300^{\circ} \mathrm{C}$, (d) $400^{\circ} \mathrm{C}$ and (e) $500^{\circ} \mathrm{C}$

\subsection{Morphological Properties of the CdS Films}

The optical microscope images and AFM micrographs three-dimensional (3D) of the as-deposited and annealed cadmium sulfide films are shown in Figure 7-8, respectively. AFM micrographs show that the morphology of the film changes with annealing. The AFM micrographs of all the cadmium sulfide films showed a structure of valleys and hills with some empty spaces. The surface roughness of cadmium sulfide films increase with the increasing of the annealing temperature. These might happen because of the differences in crystallite size of the CdS films [5, 15, 26]. From optical microscope images, the color of the film was found to change from an orange and greenish yellow to pale green and finally to greenish yellow with the rising of the annealing temperature $[27,28]$.
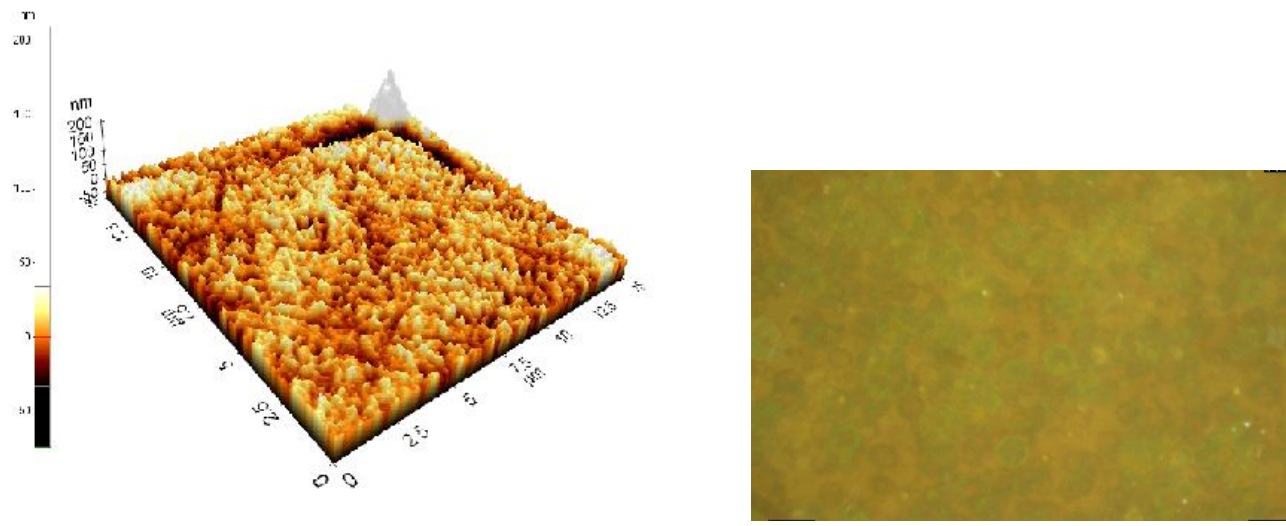

Figure 7. AFM micrographs 3D (left) and optical microscope images (right) of as-deposited of cadmium sulfide films. 

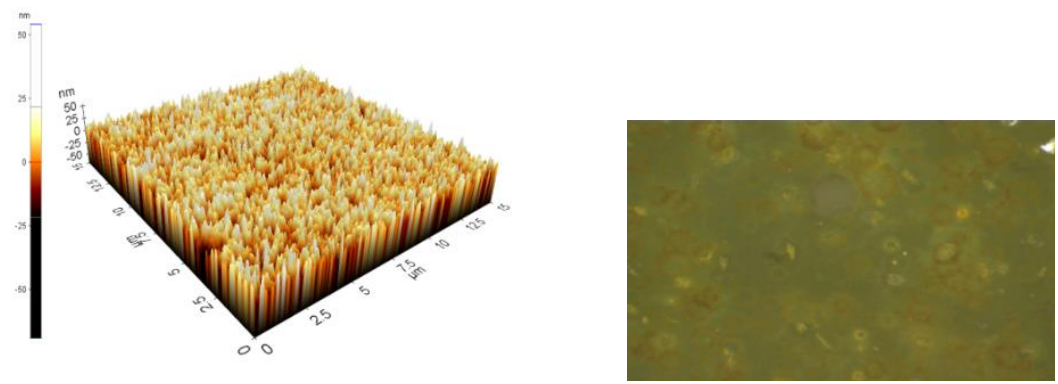

(a)
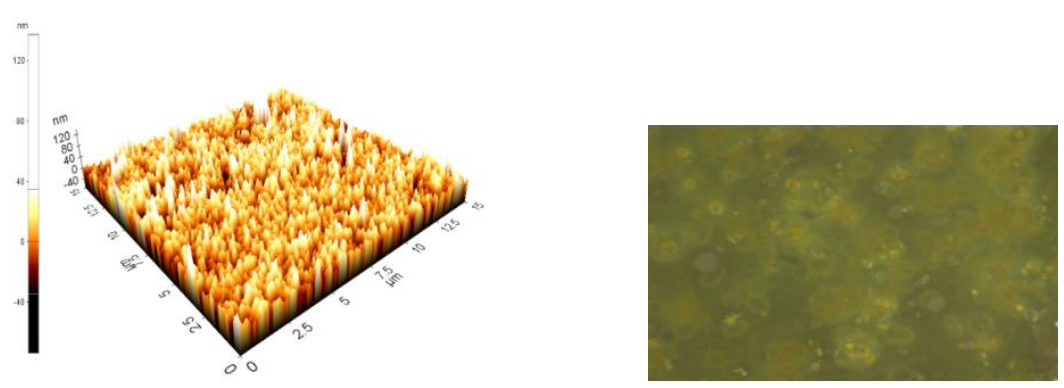

(b)
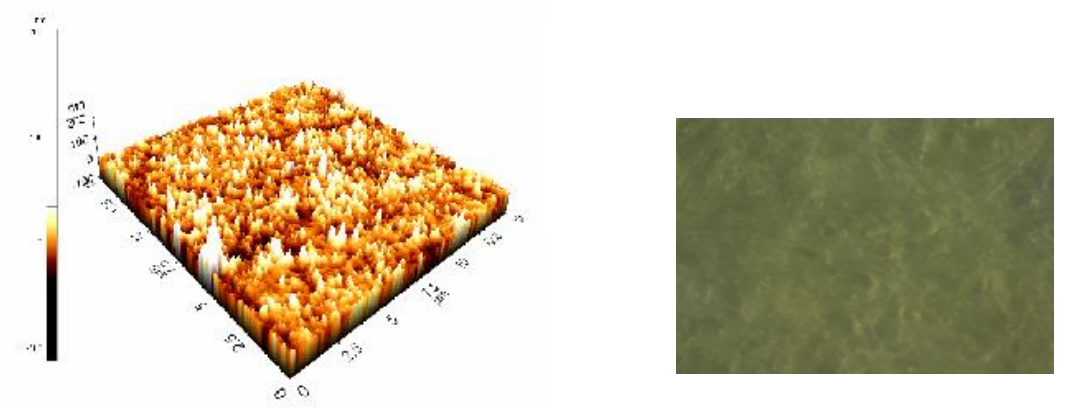

(c)
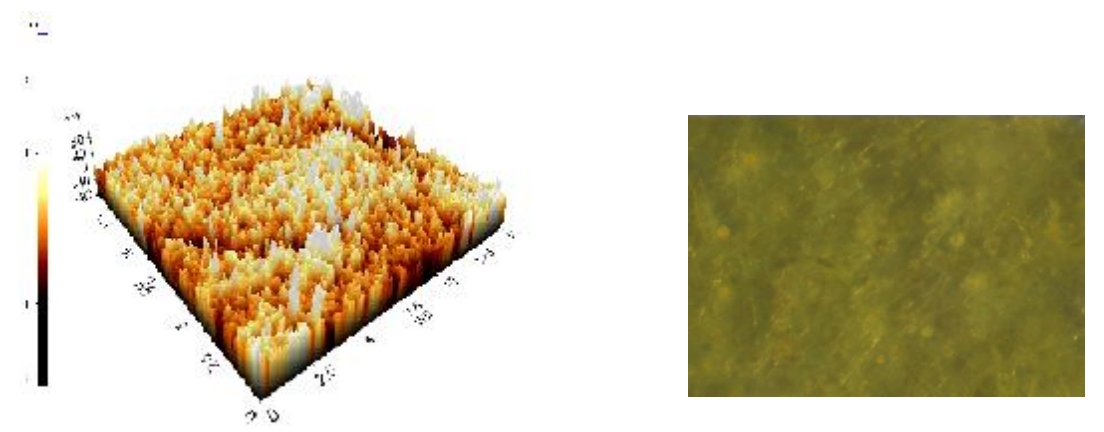

(d)

Figure 8. AFM micrographs 3D (left) and optical microscope images (right) of cadmium sulfide films annealed at (a) $200^{\circ} \mathrm{C}$, (b) $300^{\circ} \mathrm{C}$, (c) $400^{\circ} \mathrm{C}$, and (d) $500^{\circ} \mathrm{C}$ 


\section{CONCLUSION}

In this study, cadmium sulfide films were deposited by a simple USP method on to a glass base and then the films were annealed at $200,300,400$ and $500^{\circ} \mathrm{C}$ air for 5 hours. The effects of the annealing temperature on vibrational, structural, optical and morphological aspects of $\mathrm{CdS}$ films were analyzed, respectively, FTIR, Raman, XRD, UV-vis, and AFM studies. Wurtzite structure of CdS films was confirmed from XRD and Raman result. The crystallite size for the films was found to be in the range of 29-35 nm, depending on the annealing temperature. The energy band gap values found to be from $2.40 \mathrm{eV}$ to $2.44 \mathrm{eV}$ with an annealing temperature. Raman measurements revealed two peaks corresponding to the $1 \mathrm{LO}$ and $2 \mathrm{LO}$ modes of hexagonal CdS. The vibrational phonon modes of $\mathrm{Cd}-\mathrm{S}$ were detected in the wavenumber range $\left(550-715 \mathrm{~cm}^{-1}\right)$ using FTIR. The atomic force micrograph of all the films were investigated. These images changed with the annealing temperature.

\section{ACKNOWLEDGEMENTS}

I would like to thank to Mrs. Özge Bağlayan (vibrational spectroscopy measurement), Mrs. Meryem Polat Gönüllü (XRD measurement) and Mr. Salih Köse (the production of the films).

\section{REFERENCES}

[1] Shaban M, Mona M, Sayed A.M. El. Structural, optical, and photocatalytic properties of the spray deposited nanoporous CdS thin films; influence of copper doping, annealing, and deposition parameters. Mater Sci in Semicond Processing 2016; 56:329-343.

[2] Kwon J, AHN J. S.b and Kwon H. Y. Chemical bath deposition of CdS channel layer for fabrication of low temperature processed thin-film-transistors. Current Applied Physics 2013; 13:84-89.

[3] Sathiya Priya N, Shalini Packiam Kamala S, Anbarasu V, Anbuchudar Azhagan S, Saravanakumar R. Characterization of CdS thin films and nanoparticles by a simple Chemical Bath Technique. Mater Letters 2018; 220: 161-164.

[4] Ojeda-Barrero G, Oliva-Avilés A.I, Oliva, Maldonado R.D, Acosta M, Alonza-Medina G.M. Effect of the substrate temperature on the physical properties of sprayed-CdSfilms by using an automatized perfume atomizer. Mater Sci in Semicond Processing 2018; 79: 7-13.

[5] Meher S, Kaushik Deepak K, Subrahmanyam A. Native defects in sol-gel derived CdS buffer layers for photovoltaic applications. J Mater Sci Mater Electron 2017; 28: 6033-6046.

[6] Kim, D., Park, Y., Kim, M., Choi, Y., Park, Y.S., Lee, J., Optical and structural properties of sputtered CdS films for thin film solar cell applications. Mater Res Bull, 2015; 69: 78-83.

[7] Memarian N, Rozati S.M, Concina I, Vomiero A. Deposition of Nanostructured CdS Thin Films by Thermal Evaporation Method: Effect of Substrate Temperature. Mater 2017; 10:7, 773-781.

[8] Kong L, Li J, Chen G, Zhu C, Li1 W. A comparative study of thermal annealing effects under various atmospheres on nano-structured CdS thin films prepared by CBD. J of Alloys and Comp 2013; 573: $112-117$.

[9] Khallaf H, Chai G, Lupan O, Chow L, Park S and Schulte S. Investigation of aluminium and indium in situ doping of chemical bath deposited CdS thin films J Phys D Appl Phys 2008; 41:185304185313. 
[10] Liu F, Lai Y, Liu J, Wang B, Kuang S, Zhang Z, Li J, Liu Y. Characterization of chemical bath deposited CdS thin films at different deposition temperature. J of Alloys and Comp 2010; 493:305308.

[11] Atay F, Bilgin V, Akyüz I, Köse S. The effect of In doping on some physical properties of CdS films. Mater Sci Semicond Processing 2003; 6: 197-203.

[12] Özer T, Aksay S, Köse S. Fourier transform infrared and Raman spectroscopic properties of $\mathrm{Cd}_{1-\mathrm{x}} \mathrm{Sb}_{\mathrm{x}} \mathrm{S}$ films deposited by ultrasonic spray pyrolysis. The European Physical J Applied Physics 2010; 51:11501-11503.

[13] Aksay S, Polat M, Özer T, Köse S, Gürbüz G. Investigations on structural, vibrational, morphological and optical properties of $\mathrm{CdS}$ and $\mathrm{CdS} / \mathrm{Co}$ films by ultrasonic spray pyrolysis. Applied Surface Science 2011; 257: 10072-10077.

[14] Chaku A.K, Singh P. K, Bhattacharya B, Cadmium zinc sulphide (Cd1-xZnxS) films: effect of annealing. J Mater Sci Mater Electron 2017; 28:11163-11171.

[15] Akbarnejad E, Ghorannevis Z, Abbasi F, Ghoranneviss M. Investigation of annealing temperature effect on magnetron sputtered cadmium sulfide thin film properties. J Theor Appl Phys 2017; $11: 45-49$.

[16] Chander S, Dhaka M.S. Thermal annealing induced physical properties of electron beam vacuum evaporated CdZnTe thin films. Thin Solid Films 2017; 625:131-137.

[17] Arunraja L, Thirumoorthy P, Karthik A, Sriram G, Rajendran V, L.Edwinpaul L. Structural and Electrical Properties of Cadmium Sulfide Nanoparticles: A Simple Chemical Route. Synthesis and Reactivity in Inorganic, Metal-Organic, and Nano-Metal Chemistry 2016; 46: 1642-1646.

[18] Powder Diffraction File, Joint Committee on Powder Diffraction Standards, ASTM, Philadelphia, PA, 1967, Card 006-314 and 041-1049.

[19] Powder Diffraction File, Joint Committee on Powder Diffraction Standards, ASTM, Philadelphia, PA, 1967, Card 020-1225

[20] B.D. Cullity, S.R. Stock, Elements of X-ray Diffraction, $3^{\text {rd }}$ ed.,Prentice Hall, 2001.

[21] Aggarwal1 R, Ram Sankar P, Sahu1 A, Ingale A.A, A. K. Sinha A.K, Mukherjee C. Template based room temperature growth of high density $\mathrm{CdS}$ nanowires from aqueous electrolyte using high frequency alternating current. J Mater Sci Mater Electron 2018; 29: 427-435.

[22] Fan T, Li Y, Shen J, Ye M. Novel GQD-PVP-CdS composite with enhanced visible-light drivenphotocatalytic properties. Applied Surface Science 2016; 367: 518-527.

[23] J. Tauc (Ed.), Amorphous and Liquid Semiconductors, Plenum Press, New York 1974.

[24] Bacaksiz E, Tomakin M, Altunbas M, Parlak M, Çolakoğlu T. Structural, optical and magnetic properties of $\mathrm{Cd}_{1-x} \mathrm{Co}_{x} \mathrm{~S}$ thin films prepared by spray pyrolysis. Physica B 2008; 403: 3740-3745.

[25] Çetinörgü E, Gümüş C, Esen R. Effects of deposition time and temperature on the optical properties of air-annealed chemical bath deposited CdS films. Thin Solid Films 2006; 515: 1688-1693. 
[26] Sivaramamoorthy K, Asath Bahadura S, Kottaisamya M, K.R. Muralia K R. Properties of CdS films deposited by the electron beam evaporation technique. Journal of Alloys and Compounds 2010; 503: 170-176.

[27] Mahdavi S.M, A. Iraji zad, R.M. Tilaki. The effect of target annealing temperature on optical and structural properties and composition of CdS thin films prepared by pulsed laser. Optical Mater 2005; 27: 1583-1586.

[28] Abken A.E, Halliday D.P, Durose K. Photoluminescence study of polycrystalline photovoltaic CdS thin film layers grown by close-spaced sublimation and chemical bath deposition. $\mathrm{J}$ of Applied Physics 2009 105: 064515-9. 